\title{
Health Seeking Behavior: Concept Analysis
}

Cynthia Eka Fayuning Tjomiadi ${ }^{{ }^{*}}$

${ }^{1 *}$ Faculty of Nursing, Khon Kaen University, Thailand

E-mail: tjomiadicynthia@gmail.com

Pattama Surit

${ }^{1 *}$ Faculty of Nursing, Khon Kaen University, Thailand

pattama_surit@gmail.com

\begin{abstract}
Objective: To determine a conceptual definition of health seeking behavior.

Methods: Walker and Avant (2011) method of concept analysis approach. The author identified the attributes, antecedents, consequences, empirical referents, and create case description of the concept including model case, borderline case and contrary case. The review literature from thirty-nine separate sources were chosen from database searches of Proquest, CINAHL and PubMed accessed from the University's library website. Others information relating to health seeking behavior was included from some pages of a related website. Key terms utilized for the search were "health seeking behavior" OR "health seeking" OR "health behavior"

Results: Health seeking behavior described as the action or inaction of individual which responding to the stimuli to achieve optimum well-ness.

Conclusion: Health seeking behavior described as the action or inaction of an individual which responding to the stimuli to achieve optimum well-ness. It has clearly described the differences of this concept with another concept that has a close definition such as help seeking behavior, and health information seeking behavior.
\end{abstract}

Keywords: Concept analysis, Health Seeking Behavior, Health, Behavior, Seeking

\section{INTRODUCTION}

Nurses as one of main component in health system have to involve in a wide range of various diseases [1]. It made nurse have to understand the phenomena in health area deeply. One of the most trending phenomena which occur is health and behavior. There are numerous theories and studies which explain about how behavior can influence the health outcome of individuals, it needs a deep understanding to get the explanation of the factors that drive individuals performed the health seeking behavior [2]. The concept of health seeking behavior has been used widely as a framework in health care system. Many articles or journals has mentioned it as an action which an individual makes a decision making to find a support to complete his/her personal need that is related to illness condition [2-4]. Health seeking behavior concept is related to the role of the nurse in nursing metaparadigm which is to enhance the health potential among individuals by influencing them to make a change in their behavior that can lead to the optimum wellness [5]. Moreover, has been discovered that health seeking behavior is a multidimensional concept which relied on time and context [6]. According to this finding, the multidisciplinary approach of health seeking behavior concept analysis is urgently needed to help nurse get a clear picture of the concept of health seeking behavior.

A concept is constructed by phrases that explaining the phenomena that experienced by individuals. It can be complex and interfere with one to another. There are two concepts that have similarities with health seeking behavior. The first one is help seeking behavior [1], which defined as 
intended action to overcome the problem that stimulates personal capability. The second, health information seeking behavior [7] which defined as the way patients find and use health information beyond health care contexts that determined by stressful health challenges. Those existing concepts can be confusing for health care providers especially the nurses. With a clear and strong definition of it, nurses will able to identify the causes, attributes, antecedents and consequences of the concept. It will help the nurses to be able to decrease the delayed diagnose, increase the adherence to treatment and as a guide for health promotion strategies. Finally, the quality practice of the nurses will be improved [8]. Furthermore, a researcher cannot persistently develop the measurement tools without a clear definition of the concept. Clear definitions of the concept are used as validation item for the measurement tools (9). This paper will distinguish the meaning of health seeking behavior deeply by using a multidisciplinary approach in order to give the firm and specific explanation and outline the main item of this concepts. The result of this paper will help the nurse and future researcher to develop a valid measurement and finally, it will add more value to body knowledge of nursing science. Thus, the objective of this paper is to determine a conceptual definition of health seeking behavior.

\section{METHODS}

Concept analysis is a method that used in term of finding the explanation or the distinct meaning of a concept by logically and systematically investigating many references such as journals, article, and paper.

Walker and Avant's (2011) method of concept analysis approach were used in this paper. Supporting articles for this paper were retrieved from Proquest, CINAHL and PubMed accessed from the University's library website. Others information relating to health seeking behavior was included from some pages of a related website. Furthermore, several attributes and cases were identified to clarify the concept of health seeking behavior.

\section{RESULTS AND DISCUSSION}

Walker and Avant's (2011) concept analysis was including definition, defining attributes, model case, borderline case, contrary case, antecedents, consequences and empirical referents. In this paper, in order to get the explanation deeply, the author analyze multiple resources and publication from many disciplines that have a different meaning of the concept. The health seeking behavior consist of 3 words which are health, seeking and behavior. Use of the concept as follows:

\section{USE OF HEALTH CONCEPTS}

The word "health" basically came from Old English which means the condition of being sound or whole in a positive way and it is associated with physiological functioning, moral and spiritual [10]. Moreover, World Health Organization defined health as 'a state of complete physical, mental and social wellbeing and not merely the absence of disease and infirmity' [11]. Others definitions of "health" from dictionaries as follows:

1. A state which characterized by optimal function and absence of disease and abnormality" [12]

2. Health is a state of physical and psychological well-being and of productivity including reproduction [13]

3. Health is a state of an organism when it functions optimally without evidence of disease or abnormality [14]

Furthermore, health is also defined by many philosophers such as:

1. Philosophers in nursing, Betty Neuman state health is a continuum of wellness to illness that is dynamic in nature [15].

2. Sister Callista Roy define health as "Health is not freedom from the inevitability of death, disease, unhappiness, and stress, but the ability to cope with them in a competent way." [16].

3. Health as "the expression of the success or failure experienced by the organism in its efforts to respond adaptively to environmental changes" [17].

From those definitions of health, it can be concluded health is the dynamic state of 
continuum physical, psychological, social wellbeing of individuals, characterized by optimal function, absence of a disease and abnormality, and respond adaptively to environmental changes.

\section{USE OF SEEKING CONCEPTS}

Seeking is came from the word "seek" that has a meaning as attempt or desire to obtain or achieve (something) [18]. The word "seek" can used as a verb and as a noun. As a verb, it means to go in search of, look for, discover, ask for, try to acquire or gain, or to make an attempt. As a noun, it denotes a series of notes upon a horn calling out to hounds to begin a chase [19]. Moreover, when the word "seek" used with some nouns it make adjectives meaning for looking for something or trying to get something. For examples: attentionseeking children, publicity-seeking antics [20]. To summarize, the world seek is attempt to achieve something by searching of, looking for, discover, asking for, try to acquire or gain.

\section{USE OF BEHAVIOR CONCEPTS}

Most of the behavior concepts are used in social psychology [21]. Behavior can be defined as the way in which an individual behaves or acts. It is the way an individual conducts herself/himself [25]. Moreover, behavior describe as an attempt of an individual to make a change from one state of affairs to another or to maintain a current state of affairs [22].

Furthermore, in biological disciplines behavior is either actions or inactions of the internally coordinated responses from whole living organisms (individuals or groups) toward internal and/or external stimuli, on the other hand easily understood as developmental changes [23]. Moreover, the analysis of behavior defines it as action from a person that can be observed, measured, and repeated [24].

Behavior also categorized by physiological, situational and aptitudinal functions [25, 26]. The details as follows:
1. 'physiological' end-states, which provide changes to evolutionary benefits themselves

2. 'situational' end-states, which produce a changed relationship with the world, such as access to territory or status, which tend to lead to future evolutionary benefits and

3. 'aptitudinal' end-states, which produce a changed capacity to gain future situational or physiological benefits through the acquisition of knowledge or skill.

Moreover, the definition of behavior also used in economic and business disciplines. According to Minton, 2014 [27], behavior relates to the acts or reactions among an organism, an individual or a system in order to response to a particular circumstance. The response could be convinced by internal or external stimuli or inputs from the environment. In the same way, behavior defined as a response of an individual or group to an action, environment, person, or stimulus [28].

To sum up, behavior is the way of the individual to act or in act to internal \& external stimuli. The respond can be observed, measure and repeated in and attempt to change from one state of affairs to another that is related to biological, physiological, situational or aptitudinal changes.

\section{DEFINING ATTRIBUTES}

Defining Attributes are the characteristic of each concept that frequently appear in several literatures. The characteristic is constantly appear in most of those references that has been founded by the authors.

1. Action or inaction of an individual which responds to internal and external stimuli

2. Action that is attempted to change one state of affair to another that is related to biological, psychological, situational, aptitudinal changes

3. Action can be measured, observed, and repeated.

4. Action that is attempted to achieve optimal function, absence of disease and abnormality, and adaptation to environmental changes 
5. Action that seeks for, looks for, asks for, or acquires for health

\section{CONSTRUCTED CASE}

Constructed case is the way to help people understand the concept by giving an example of real situation that happened. The example will be categorized into three level case which are model case, borderline case and contrary case.

\section{MODEL CASE}

Model case is the example of the real situation that happened with the use of all attribute of the concept.

Mrs.N has been diagnosed DM since 12year ago. She had an experience of diabetic foot ulcer (DFU) one-year ago. She worried she will have a diabetic foot ulcer again in the future. She tries to change her lifestyle in order to prevent the $D F U$. She performed foot care and foot exercise every day. She followed all the instructions from the health care provider. She also never missed any appointments to see the doctor for a routine checkup. She quits to eat sweets food and started to control her diet. At the end, she lives well without developed any reoccurrence of DFU.

Based on model line case, we can see that Mrs.N do the health seeking behavior completely. The health seeking is Mrs.N and she identified the risk for DFU recurrence. She took an action in order to achieve optimum wellness which is referred to absence of the DFU incidence. She changed her behavior and repeated it over the time. At the end she achieve optimum wellness without developed the DFU.

\section{BORDERLINE CASE}

Borderline case, is contain only some of the attribute or in another word, the case that didn't do all the attribute completely or imperfect model case.

Mrs.N has been diagnosed DM since 12year ago. She had an experience of diabetic foot ulcer (DFU) one-year ago. She does not worried about the recurrence of the DFU. The nurse and her family tried to ask her to do the foot care and foot exercises regularly and have a healthy diet. However, she followed all those instructions in temporary time. She gets bored and often forgot to take medications and control her diet. At the end, she develops the DFU again.

From the borderline case, Mrs.N didn't do a health seeking behavior completely. She only did some point of the attribute. Even though she has been performed health behavior, it does not come from herself. It has happened because the nurse and the family who force her to change her behavior. Moreover, she did not change her behavior permanently. At the end, she developed the DFU again. She has been failed to achieve optimum wellness.

\section{CONTRARY CASE}

Contrary case describe the totally different situation of the concept. Contrary case provide the example of "no attribute situation".

Mrs.N has been diagnosed DM since 12year ago. She had an experience of diabetic foot ulcer (DFU) one-year ago. She does not worried about the recurrence of the DFU. She ignores all the suggestions from the health care provider. She did not perform any health behavior changes. At the end, she develops the DFU again.

From the case, there is no action of Mrs.N to response to the internal or external stimuli to achieve optimal well ness. Mrs.N didn't adapt well to environmental changes.

\section{ANTECEDENTS}

Antecedents are events that have happened before the occurrence of the concept. There are several main factors of health seeking behavior that has been founded from the literature review. A family with younger and higher number of family members are likely to engage with health services, whereas the individual adult family member has a less effort to seek the health treatment [29]. Moreover, strong cultural beliefs on traditional healers and the cause of the disease strongly influence the health seeking behavior patterns, including the 
limitation of quality of care and availability of drugs that worsens the health seeking behavior pattern [30]. Furthermore, in term of economic factor, the less income families were likely to avoid health seeking behavior, whereas the higher income families tend to perform health seeking behavior [31]. The others determinant factor is related to disease pattern. Perceived severity of illness makes people give higher intention to do health seeking behavior [32]. It can be concluded that the health seeking behavior is accented on some determinant factors which are family members, cultural, economic, disease pattern and issues related to health services [6]

\section{CONSEQUENCES}

Consequences are the situation that happened after the occurrence of the concept. According to research from Maneze, et.al., 2015 [33], change in health seeking behavior is effective and sustainable in reducing risk factors for lifestyle diseases. Another research from Derose, Escarce, \& Lurie, 2007 [34] and Musoke, 2014 [3] discovers that health seeking behavior are relate to the health outcomes. In line with those research, a research from Abidin, et al., 2014 [35] found that health seeking behavior can prevent the complication of the chronic disease and also enhance the awareness in prevention program for communicable disease [36]. Shortly, people who performing health seeking behavior are likely to report a better health. Assuming that health seeking behavior has occurred, the outcome of individual health status will be good and they will able to reach the optimum level of wellness.

\section{EMPIRICAL REFERENTS}

Research on health seeking behavior has been widely recognized for contributing in development of the understanding how and why people do the behavior change to reach the wellness states. Numerous theories have been explained to predict health seeking behavior such as Health Belief Model, Theory Reasoned Action, Theory of Planed Behavior, and Transtheoretical Model [2] Those theories are explaining how the perceptions or attitude of individuals become the significance aspect of behavior construct.
Moreover, a systematic review from Adams, 2010 [37] discovered that education intervention is effective intervention to improve the health seeking behavior. The education interventions to improve the health seeking behaviors should be adjusted to the target population or socioeconomic target group. Some of the education techniques may need a multi kind of the design. For the literacy population, the education package might not only consist of the books or papers based. It will be better if the package has another kind of education tools such as video tape or has more pictures than the text. Furthermore, the long term evaluation is meaningful to do in order to evaluate the effectiveness of the intervention that has been applied.

Furthermore, in several literatures describe health seeking behavior as different definitions based on particular attributes of health seeking behavior, Abidin, Sutan, \& Shamsuddin [35] describe health seeking behavior as the action of individuals who visiting any health facilities (government or private) and using modern treatment instead of traditional therapy. Moreover, Peng, Chang, Zhou, Hu, \& Liang, [38] defined health seeking behavior as an action of individual who go the see the doctor when they perceived the sign and symptom of the diseases. In term of qualitative study, Abubakar, et al., 2013 [39] describes the health seeking behavior in particular population comprehensively. It discovered how the population take an action and make a decision when they perceived the severity of the disease, their perception towards the disease, how they prevent the disease and factors associated with postponing the health seeking behavior.

Health seeking behavior research are strongly associated to the nursing practice. Since the nurse mostly engage with nonmedical activities, it makes nurses are responsible for enhance the behavior change and emphasize the self-care capabilities among individuals. 


\section{CONCLUSION}

To sum up, health seeking behavior described as the action or inaction of individual which responding to the stimuli to achieve optimum well-ness. It has clearly described the differences of this concept with another concept that has a close definition such as help seeking behavior, and health information seeking behavior. It will help

\section{REFERENCES}

[1]. Cornally, N., \& McCarthy, G. Helpseeking behaviour: A concept analysis. International Journal of Nursing Practice, 17, 280-288. https://doi.org/10.1111/j.1440172X.2011.01936.x. 2011.

[2]. Metta, E. O. Health-seeking behaviour among adults in the context of the epidemiological transition in Southeastern Tanzania: A focus on malaria and diabetes [Groningen]: University of Groningen. 2016.

[3]. Musoke, D., Boynton, P., Butler, C., \& Musoke, M. B. Health seeking behaviour and challenges in utilising health facilities in Wakiso district, Uganda. African Health Science, 14(4), 1047-1055.

https://doi.org/http://dx.doi.org/10.4314 /ahs.v14i4.36. 2014.

[4]. Klemenc-ketis, Z., \& Kersnik, J. HEALTH SEEKING BEHAVIOUR IN GENERAL. Psychiatria Danubina, 26(2), 181-186. 2014.

[5]. Thorne, S. E., \& Hall, W. A. Nursing' s metaparadigm concepts : Disimpacting the Debates. Journal of Advanced Nursing, 27(January), 1257-1268. https://doi.org/10.1046/j.13652648.1998.00623.x. 2002.

[6]. Poortaghi, S., Raiesifar, A., Bozorgzad, P., Golzari, S. E. J., \& Parvizy, S. Evolutionary concept analysis of health seeking behavior in nursing : a systematic review. BMC Health Services Research, 15, 1-8. https://doi.org/10.1186/s12913-0151181-9. 2015. nurse and other health care profession to identify cause of this concept and the consequences of it. Similarly this will help health profession learn how people engage with health care systems in their respective socio-cultural, economic and demographic circumstances. Moreover, future research can use the attributes of this concepts analysis as the validation of their research instruments.

[7]. Lalazaryan, A., \& Farashbandi, F. Z. A Review of models and theories of health information seeking behavior. Introduction After the Second World War and with the Increase in Scientific and Technical Information, the Subject of Information Seeking Behavior Was First Introduced in the Scientific Information Conference of Royal Society in 1948. This Started a New a, 2(4), 193-203. https://doi.org/10.4103/23479019.144371. 2014.

[8]. Bousso, R. S., Poles, K., \& da Cruz, D. de A. L. M. Nursing concepts and theories. Theoretical Study, 48(1), 141145. https://doi.org/10.1590/S0080623420140000100018. 2013.

[9]. Mcneill, C. Risk : A Multidisciplinary Concept Analysis. Nursing Forum, 49(1), 11-17. 2014.

[10]. Boruchovitch, E., \& Mednick, B. R. The meaning of health and illness : some considerations for health psychology. Psico-USF, 7(c), 55-64. Retrieved from http://dx.doi.org/10.1590/S141382712002000200006. 2002.

[11]. World Health Organization (WHO). Working together for health. Retrieved from http://www.who.int/whr/2006/whr06_e n.pdf. 2006.

[12]. health. (n.d.) Illustrated Dictionary of Podiatry and Foot Science by Jean Mooney. Retrieved October 20th 2017 from http://medicaldictionary.thefreedictionary.com/health. 2009. 
[13]. health. (n.d.) Saunders Comprehensive Veterinary Dictionary, 3 ed.. Retrieved May 242017 from http://medicaldictionary.thefreedictionary.com/health. 2007.

[14]. health. (n.d.) Farlex Partner Medical Dictionary. Retrieved October 20th 2017 from http://medicaldictionary.thefreedictionary.com/health. 2012.

[15]. Neuman B. The Neuman systems model. In Neuman B., Fawcett J. (Eds.), The Neuman systems model (5th ed., pp 3-33). Upper Saddle River, NJ: Pearson Education. 2011.

[16]. Roy, Sr, C., \& Andrew, H. A. The Roy Adaptation Model: The Definitive Statement. Norwalk, CT: Appleton \& Lange. 1999.

[17]. Simmons, S. J. Health: a concept analysis. Int. J. Nurs. Stud., 26(2), 155161. Retrieved from https://pmr.uchicago.edu/sites/pmr.uchi cago.edu/files/uploads/Simmons_Health AConceptAnalysis .pdf. 1989.

[18]. seek. (n.d). Merriam-Webster Online Dictionary. Retrievd October 20th, from https://www.merriamwebster.com/dictionary/seek. 2016

[19]. Hooper, G. L., \& Quallich, S. A. Health Seeking in Men : A Concept Analysis. Urologic Nursing, 36(4), 163-171. https://doi.org/10.7257/1053816X.2016.36.4.163. 2016.

[20]. seek. (n.d.). Collins English Dictionary - Complete \& Unabridged 10th Edition. Retrieved October 20th, from Dictionary.com website http://www.dictionary.com/browse/seek 2016.

[21]. Morris, J., Marzano, M., Dandy, N., \& Brien, L. O. Forestry, sustainable behaviours and behaviour change setting the scene Summary Report. Retrieved from https://www.forestry.gov.uk/pdf/behavi our_review_summary.pdf/\$file/behavio ur_review_summary.pdf. 2012

[22]. Bergner, R. M. What is behavior? And so what? New Ideas in Psychology, 29(2), 147-155. https://doi.org/10.1016/j.newideapsych.
2010.08.001. 2011.

[23]. Levitis, D. A., Jr, W. Z. L., \& Freund, G. NIH Public Access. National Institutes of Health, 78(1), 103-110. https://doi.org/10.1016/j.anbehav.2009. 03.018. 2010.

[24]. Bicard, S. C, Bicard, D. F., \& the IRIS Center. Defining behavior. Retrieved on [October 20th ， 2016] from http://iris.peabody.vanderbilt.edu/case_s tudies/ ICS-015.pdf. 2012.

[25]. Boyd, R. Realism, AntiFoundationalism and Enthusiasm for Natural Kinds. Springer, 61(1), 127148. 2015.

[26]. Millikan, R. G. In Defense of Proper Functions Author ( s ): Ruth Garrett Millikan Source : Philosophy of Science, Vol . 56 , No . 2 ( Jun ., 1989 ), pp . 288-302 Published by : The University of Chicago Press on behalf of the Philosophy of Science Association Stable UR. Chicago Journals, 56(2), 288-302. https://doi.org/10.1086/289488. 2013.

[27]. Minton, E.A., \& Khale, L.R. Belief Systems, Religion, and Behavioral Economics. New York: Business Expert Press LLC. ISBN 978-1-60649-704-3. 2014.

[28]. BusinessDictionary.com. Retrieved October 20th, 2017, from BusinessDictionary.com website: http://www.businessdictionary.com/defi nition/business.html

[29]. Sepehri, A., Moshiri, S., Simpson, W., \& Sarma, S. Taking account of context : how important are household characteristics in explaining adult health-seeking behaviour ? The case of Vietnam. Health Policy and Planning, 23(September), 397-407. https://doi.org/10.1093/heapol/czn034. 2008.

[30]. Chibwana, A. I., Mathanga, D. P., Chinkhumba, J., \& Jr, C. H. C. Malaria Journal. Malaria Journal, 8, 1-8. https://doi.org/10.1186/1475-2875-8219. 2009.

[31]. Gerald, M. Assessing Factors Influencing Health Seeking Behavior for Malaria Treatment in Children under 
Five Years in Rwimi Town Council Kabarole District. International Journal of School and Cognitive Psychology, 2(4), 1-7. https://doi.org/10.4172/24699837.1000151. 2015.

[32]. Webair, H. H., \& Bin-Gouth, A. S. Factors affecting health seeking behavior for common childhood illnesses in Yemen. Patient Preference and Adherence, 7(October), 1129-1138. Retrieved from http://dx.doi.org/10.2147/PPA.S51124. 2013.

[33]. Maneze, D., Digiacomo, M., Salamonson, Y., Descallar, J., \& Davidson, P. M. Facilitators and Barriers to Health-Seeking Behaviours among Filipino Migrants : Inductive Analysis to Inform Health Promotion. BioMed Research International, 2015, 1-9. Retrieved from http://dx.doi.org/10.1155/2015/506269. 2015.

[34]. Derose, K. P., Escarce, J. J., \& Lurie, N. Immigrants And Health Care : Health Affairs, 5(5), 1258-1268. https://doi.org/10.1377/hlthaff.26.5.125 8. 2007.

[35]. Abidin, Z. S. I., Sutan, R., \& Shamsuddin, K. Prevalence and Determinants of Appropriate Health Seeking Behaviour among Known Diabetics: Results from a CommunityBased Survey. Advances in Epidemiology, 2014(November). https://doi.org/10.1155/2014/793286.

2014.

[36]. Nwoke, E. A., Ibe, S. N. O., Chukwuocha, U. M., \& Nworuh, B. O. The Impact of Health Seeking Behaviour, Educational Attainment and Financial Strength on Home Management of Malaria in Rural Communities in Imo State, Nigeria. British Journal of Medicine \& Medical Research, 4(15), 2884-2895. 2014.

[37]. Adams, R. J. Improving health outcomes with better patient understanding and education. Risk Management and Healthcare Policy, 3, 61-72.
https://doi.org/10.2147/RMHP.S7500 2010.

[38]. Peng, Y., Chang, W., Zhou, H., Hu, H., \& Liang, W. Factors associated with health-seeking behavior among migrant workers in Beijing, China. BMC Health Services Research, 10(69), 1-10. https://doi.org/10.1186/1472-6963-1069.2010.

[39]. Abubakar, A., Baar, A. Van, Fischer, R., Bomu, G., Gona, J. K., \& Newton, C. R. Socio-Cultural Determinants of Health-Seeking Behaviour on the Kenyan Coast : A Qualitative Study. PLOS ONE, 8(11), 1-8. https://doi.org/10.1371/journal.pone.00 71998. 2013. 